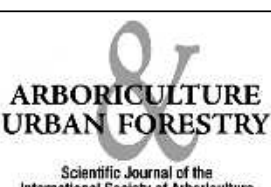

\title{
Assessing Urban Forest Structure: Introduction
}

This special issue of Arboriculture and Urban Forestry contains a series of papers related to assessing urban forest structure. These papers were presented at a joint International Society of Arboriculture (ISA) and International Union of Forest Research Organizations (IUFRO) Urban Forestry Research Group session at the 83rd Annual ISA Conference in Honolulu, Hawaii. This joint session solicited papers from around the world on methods of assessing urban forest structure. Accurate information describing urban forest structure (e.g., species composition and diversity, number of trees, tree size distribution, tree health) is an important prerequisite for assessing urban forest functions and values, and is critical to developing urban forest management plans. In addition, urban forest structure assessments can be used to better understand the similarities and differences in vegetation among cities from across the globe.

Authors were encouraged to detail methods of data collection and discuss advantages and disadvantages of the data collection and analysis approach. Some of the goals of this special issue are to determine the commonalities among data collection methods, reasons for data collection, and potential advantages and disadvantages of data collection techniques. Papers in this special issue include assessing urban forest structure from aerial-based platforms (top-down approach) as well as several papers dealing with field data collection (bottom-up approach). It is hoped that this special issue will encourage more and improved urban forest data collection across the globe, as well as a standardization of data collection techniques to facilitate data collection and intercomparisons among cities internationally.

David J. Nowak

USDA Forest Service

Robert W. Miller

Editor 